\title{
ACÚMULO DE NUTRIENTES E TEMPO DE DECOMPOSIÇÃO DA PALHADA DE ESPÉCIES FORRAGEIRAS EM FUNÇÃO DE ÉPOCAS DE SEMEADURA
}

\author{
NUTRIENTS ACCUMULATION AND STRAW DECOMPOSITION TIME OF \\ FORAGE SPECIES IN FUNCTION OF SOWING TIMES
}

\author{
Nídia Raquel COSTA ${ }^{1}$; Marcelo ANDREOTTI ${ }^{2}$; Nelson de Araújo ULIAN²; \\ Bruno Soratti COSTA ${ }^{4}$; Cristiano Magalhães PARIZ ${ }^{5}$; \\ Marcelo Carvalho Minhoto TEIXEIRA FILHO ${ }^{2}$ \\ 1. Pós-Doutoranda em Agronomia, Bolsista FAPESP, Faculdade de Ciências Agronômicas - FCA - Universidade Estadual Paulista - \\ UNESP - Botucatu, SP, Brasil. nidiarcosta@gmail.com; 2. Professor, Doutor, Bolsista de Produtividade CNPq, Departamento de \\ Fitossanidade, Engenharia Rural e Solos, FE - UNESP, Ilha Solteira, SP, Brasil; 3. Mestre em Zootecnia, Faculdade de Medicina \\ Veterinária e Zootecnia - FMVZ - UNESP, Botucatu, SP, Brasil; 4. Graduado em Zootecnia, FE - UNESP, Ilha Solteira, SP, Brasil; 5. \\ Pós-Doutorando em Zootecnia, Bolsista FAPESP, FMVZ - UNESP, Botucatu, SP, Brasil.
}

RESUMO: Com o intuito de identificar o potencial produtivo das espécies forrageiras Sorghum bicolor (L.) Moench, Pennisetum glaucum (L.) R. Br. e Urochloa brizantha cv. Xaraés em função de épocas de semeadura, bem como, a posterior formação de palhada para continuidade do sistema plantio direto, avaliou-se a produtividade de massa seca, a relação $\mathrm{C} / \mathrm{N}$ e lignina/ $\mathrm{N}$ total, o acúmulo de nutrientes e a decomposição da palhada em duas safras agrícolas. $\mathrm{O}$ experimento foi realizado em Selvíria - MS $\left(20^{\circ} 18^{\prime} \mathrm{S}\right.$ e $51^{\circ} 22^{\prime} \mathrm{W}$, com altitude de $\left.370 \mathrm{~m}\right)$, num LATOSSOLO VERMELHO Distroférrico. O delineamento utilizado foi o de blocos casualizados, em arranjo fatorial $3 \times 3$, com três espécies de plantas forrageiras: sorgo forrageiro (Sorghum bicolor (L.) Moench), milheto (Pennisetum glaucum (L.) R. Br.) e o capim xaraés (Urochloa brizantha cv. Xaraés) e três épocas de semeadura (1 $1^{\mathrm{a}}$ época - 14/09/09 (E1), $2^{\mathrm{a}}$ época -

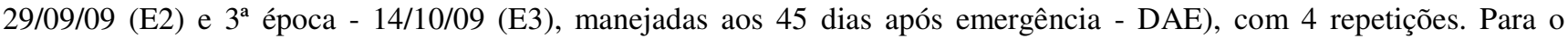
segundo ano agrícola (2010/2011), utilizaram-se as mesmas espécies forrageiras e delineamento experimental, com as seguintes épocas de semeadura: $1^{a}$ época - 10/09/10 (E1), $2^{a}$ época - 27/09/10 (E2) e $3^{a}$ época - 20/10/10 (E3), respectivamente. As maiores produtividades de massa seca e acúmulos de nutrientes foram obtidos pela cultura do sorgo forrageiro nas três épocas de semeadura. A cultura do sorgo forrageiro apresentou os maiores valores da relação $\mathrm{C} / \mathrm{N}$ e lignina/ $\mathrm{N}$ total, principalmente nas $2^{\mathrm{a}}$ e $3^{\mathrm{a}}$ épocas, nos dois anos agrícolas, proporcionando menor degradação da palhada em comparação ao milheto e ao capim xaraés. A decomposição da palhada foi mais lenta para o sorgo forrageiro e o milheto. Independentemente da espécie forrageira e da época de semeadura, a deposição inicial de massa seca das forrageiras foram adequadas para utilização destas espécies no sistema plantio direto, nas condições climáticas de cerrado de baixa altitude.

PALAVRAS-CHAVE: Sorghum bicolor. Pennisetum glaucum. Urochloa brizantha. Sistema plantio direto.

\section{INTRODUÇÃO}

Para o sucesso do sistema plantio direto (SPD), um dos requisitos indispensáveis é a boa formação da palhada na superfície do solo. Desta maneira, a correta escolha da espécie vegetal a ser utilizada é extremamente importante, uma vez que devem ser considerados os fatores climáticos característicos de cada região e tipo de solo. No Cerrado, o clima é caracterizado por inverno seco, altas temperaturas no decorrer do ano e estação seca prolongada, o que dificulta a implantação de plantas de cobertura e principalmente a permanência da palhada na área de cultivo, sendo estes fatores, um dos maiores entraves na manutenção do SPD (PACHECO et al., 2008).

Culturas como o milheto, o sorgo forrageiro e capins do gênero Brachiaria (Syn. Urochloa) em regiões de Cerrado (PARIZ et al., 2011b; COSTA et al. 2012) são consideradas excelentes opções para utilização em sistemas conservacionistas como o SPD e vem sendo muito usadas do outono a primavera para fornecimento de forragem e/ou palhada nestes sistemas produtivos. Assim, a palhada torna-se de fundamental importância para a consolidação e manutenção do SPD.

Conforme Macedo (2009), a adoção do SPD é altamente dependente da produção e manutenção de palhada sobre a superfície do solo. Nesse contexto, a utilização de culturas na entressafra objetivando a cobertura do solo e a ciclagem de nutrientes torna-se importante na diversificação da produção agrícola com sustentabilidade (PARIZ et al., 2011a), assim como a permanência da palhada na superfície do solo para a manutenção e a proteção do sistema solo-planta, beneficiando a 
manutenção da umidade e favorecendo a biota do solo (CALVO et al., 2010).

Boer et al. (2007), avaliaram a ciclagem de nutrientes em solo de Cerrado utilizando amaranto, milheto e capim-pé-de-galinha semeados na entressafra e constataram que a maioria dos nutrientes são liberados de forma precoce para aproveitamento da safra seguinte, em razão da acelerada decomposição dos resíduos vegetais. Para compensar essa defasagem torna-se necessário o uso de técnicas que aumentem o acúmulo de palhada por parte das plantas de cobertura (KLIEMANN et al., 2006), sincronizando a decomposição com a taxa de liberação dos nutrientes e a demanda das culturas anuais semeadas em sucessão (GAMARODRIGUES et al., 2007).

O objetivo deste trabalho foi identificar o potencial produtivo das espécies forrageiras Sorghum bicolor (L.) Moench, Pennisetum glaucum (L.) R. Br. e Urochloa brizantha cv. Xaraés em função de épocas de semeadura, bem como, a posterior formação de palhada para continuidade do
SPD, avaliando-se a produtividade de massa seca, a relação $\mathrm{C} / \mathrm{N}$ e lignina/ $\mathrm{N}$ total, o acúmulo de nutrientes e a decomposição da palhada em duas safras agrícolas.

\section{MATERIAL E MÉTODOS}

O experimento foi conduzido nas safras de 2009/2010 e 2010/2011, na Fazenda de Ensino, Pesquisa e Extensão, pertencente à Faculdade de Engenharia, Campus de Ilha Solteira (FE/Unesp), área de Produção Vegetal, localizada no município de Selvíria-MS $\left(20^{\circ} 18^{\prime} \mathrm{S}\right.$ e $51^{\circ} 22^{\prime} \mathrm{W}$, com altitude de $370 \mathrm{~m})$. O tipo climático é Aw, segundo classificação de Köppen, caracterizado como tropical úmido com estação chuvosa no verão e seca no inverno. Na Figura 1 estão apresentados os dados de precipitação pluvial, temperatura máxima, média e mínima, além do fotoperíodo durante o período de realização do experimento.

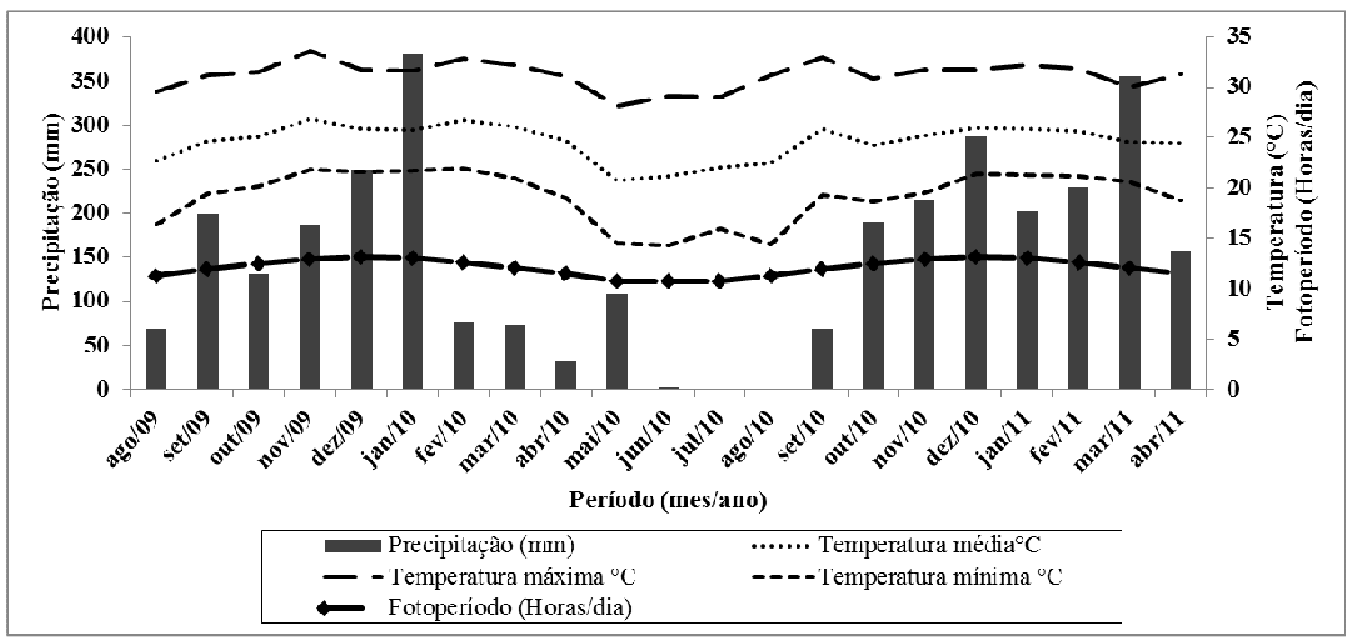

Figura 1. Dados climáticos obtidos junto à estação meteorológica situada na Fazenda de Ensino, Pesquisa e Extensão da FE/UNESP, no município de Selvíria, Mato Grosso do Sul. Período de Agosto/2009 a Abril/2011.

O solo da área experimental é um LATOSSOLO VERMELHO Distroférrico, classificado conforme Embrapa (2013). Com o objetivo de caracterizá-lo antes da implantação dos tratamentos nos dois anos agrícolas, foi efetuado um levantamento do estado da compactação e da fertilidade do solo. As análises dos atributos físicos seguiram as metodologias descritas por Embrapa (1997) e as análises dos atributos químicos seguiram as metodologias descritas por van Raij et al. (2001). Os valores para a resistência mecânica à penetração foram de 3,924 MPa $\left(\mathrm{UG}=0,203 \mathrm{~m}^{3} / \mathrm{m}^{3}\right)$ e 4,887 $\mathrm{MPa}\left(\mathrm{UG}=0,208 \mathrm{~m}^{3} / \mathrm{m}^{3}\right)$ para o ano agrícola 2009/2010 e de 4,012 MPa $\left(\mathrm{UG}=0,201 \mathrm{~m}^{3} / \mathrm{m}^{3}\right)$ e
4,896 MPa (UG=0,203 $\left.\mathrm{m}^{3} / \mathrm{m}^{3}\right)$ para o ano agrícola 2010/2011, nas camadas de 0 a 0,10 m e 0,10 a 0,20 $\mathrm{m}$, respectivamente. Os valores médios dos atributos químicos do solo encontram-se na Tabela 1.

Antes da instalação do experimento na safra 2009/2010, a área apresentava um histórico de oito anos sob sistema plantio direto (SPD) (fase inicial/transição) com culturas anuais e semiperenes para formação de palhada (milho, soja, sorgo forrageiro, guandu anão e Urochloa brizantha cv. Marandu), sendo a cultura anterior feijão de inverno. A área foi irrigada por aspersão (pivô central) considerando o intervalo hídrico ótimo para as culturas em estudo. 
Tabela 1. Caracterização dos atributos químicos do solo na profundidade de $0-0,20 \mathrm{~m}$.

\begin{tabular}{|c|c|c|c|c|c|c|c|c|}
\hline \multicolumn{9}{|c|}{ Atributos químicos do solo } \\
\hline Safra & $\begin{array}{c}\mathrm{pH} \\
\mathrm{CaCl}_{2}\end{array}$ & $\begin{array}{l}\text { M.O. } \\
\mathrm{g} \mathrm{dm}^{-3}\end{array}$ & $\begin{array}{c}\mathrm{P} \text { (resina) } \\
\mathrm{mg} \mathrm{dm}^{-3}\end{array}$ & $\mathrm{H}+\mathrm{Al}$ & $\begin{array}{r}\mathrm{K}^{+} \\
\mathrm{mmo}\end{array}$ & $\mathrm{Ca}^{2+}$ & $\mathrm{Mg}^{2+}$ & $\begin{array}{l}\mathrm{V} \\
\%\end{array}$ \\
\hline $2009 / 2010$ & 5,2 & 26,0 & 24,0 & 33,0 & 3,2 & 24,0 & 13,0 & 55,0 \\
\hline 2010/2011 & 4,9 & 25,0 & 19,0 & 38,0 & 2,4 & 20,0 & 12,0 & 48,0 \\
\hline
\end{tabular}

O delineamento estatístico utilizado foi o de blocos casualizados, em arranjo fatorial $3 \times 3$, ou seja, três espécies de plantas forrageiras: sorgo forrageiro (Sorghum bicolor (L.) Moench), milheto (Pennisetum glaucum (L.) R. Br.) e o capim xaraés (Urochloa brizantha cv. Xaraés) e três épocas de semeadura (1 ${ }^{\mathrm{a}}$ época - 14/09/09 (E1), $2^{\mathrm{a}}$ época 29/09/09 (E2) e $3^{a}$ época - 14/10/09 (E3), manejadas aos 45 dias após emergência - DAE), com 4 repetições. Para o segundo ano agrícola (2010/2011), utilizaram-se as mesmas espécies forrageiras e delineamento experimental, com as seguintes épocas de semeadura: $1^{a}$ época - 10/09/10 (E1), $2^{a}$ época - 27/09/10 (E2) e $3^{\mathrm{a}}$ época - 20/10/10 (E3), respectivamente.

Para a semeadura das espécies forrageiras na safra 2009/2010, as plantas da área foram dessecadas com herbicida Glyphosate na dosagem de $1.440 \mathrm{~g}$ do ingrediente ativo (i.a.) $\mathrm{ha}^{-1}$. Em 14/09/09 e 10/09/10 (safra 2009/2010 e 2010/2011, respectivamente), realizou-se a semeadura das espécies forrageiras com o auxílio de semeadoraadubadora para sementes pequenas com mecanismo sulcador do tipo disco duplo desencontrado para SPD. Todas as culturas foram semeadas em linha, com espaçamento entrelinhas de $0,34 \mathrm{~m}$, com uma densidade de 10-15 plantas por metro na linha de semeadura para a cultura do sorgo forrageiro "Cover Crop" e para o milheto cv. ADR 500, e utilizando-se densidade de semeadura de 532 pontos de valor cultural (VC) por hectare para o capim xaraés $(7 \mathrm{~kg}$ $\mathrm{ha}^{-1}$ de sementes puras viáveis com $\mathrm{VC}=76 \%$ ).

Posteriormente, como $2^{\mathrm{a}}$ e $3^{\mathrm{a}}$ épocas, as espécies forrageiras foram semeadas em sistema de semeadura direta, nos dois anos agrícolas analisados, respectivamente. Os espaçamentos e densidades de semeadura foram os mesmos da $1^{\text {a }}$ época para todas as espécies avaliadas nas duas safras.

O sorgo forrageiro, o milheto e o capim xaraés foram conduzidos por 45 dias após a emergência (DAE), momento este em que as plantas foram dessecadas com herbicida Glyphosate (1.440 $\mathrm{g}$ do ingrediente ativo (i.a.) ha ${ }^{-1}$ ). No dia seguinte, as espécies forrageiras foram manejadas com auxílio de um triturador horizontal de resíduos vegetais (Triton), em 05/11/09, 20/11/09 e 10/12/09, respectivamente para $1^{\mathrm{a}}, 2^{\mathrm{a}}$ e $3^{\mathrm{a}}$ épocas de semeadura (safra 2009/2010) e em 03/11/10, $18 / 11 / 10$ e $13 / 12 / 10$, respectivamente para $1^{\mathrm{a}}, 2^{\mathrm{a}}$ e $3^{\mathrm{a}}$ épocas de semeadura (safra 2010/2011).

No momento do manejo das plantas forrageiras (dessecação química e trituração), determinou-se a produtividade de massa seca (PMS) das plantas, coletando-se material em uma área de $1,0 \mathrm{~m}^{2}$ em quatro pontos distintos de cada unidade experimental com auxílio de um quadrado de metal. O corte do material vegetal foi realizado adotandose como referência $0,05 \mathrm{~m}$ em relação à superfície do solo. Desta forma, o material cortado foi pesado e as amostras colocadas em estufa de ventilação forçada de ar a $65^{\circ} \mathrm{C}$ até massa constante, sendo as quantidades extrapoladas para $\mathrm{kg} \mathrm{ha}{ }^{-1}$. Este procedimento foi realizado nas três épocas de semeadura, durante os dois anos de avaliação, respectivamente.

Após esse manejo, acondicionou-se a massa fresca de cada parcela em sacolas de decomposição confeccionas em nylon ("Litter bags" de 0,06 m², com $0,3 \times 0,2 \mathrm{~m}$ ) em quantidade proporcional ao hectare (PARIZ et al., 2011a). Os "Litter bags" foram depositados em contato direto com o solo e as espécies forrageiras utilizadas para enchimento dos sacos de nylon foram as mesmas manejadas pelo triton, simulando assim o tamanho natural dos fragmentos obtidos no manejo de corte. Aos 30, 60, 90, 120, 150 e 180 dias após o manejo (DAM), retirou-se um "Litter bag" de cada parcela, a fim de avaliar o remanescente de palhada e determinar o tempo de decomposição durante o período de 180 dias. Para isso, foi coletada a massa fresca de dentro de cada "Litter bag", que foi limpa em peneira e determinada a massa seca (estufa a $65^{\circ} \mathrm{C}$ até massa constante).

Em seguida, determinou-se os teores de $\mathrm{N}$, $\mathrm{P}, \mathrm{K}, \mathrm{Ca}, \mathrm{Mg}$ e S na palhada dos capins, conforme metodologia proposta por Malavolta et al. (1997). Os teores de macronutrientes foram multiplicados pela massa seca residual, extrapolando-se os resultados para $\mathrm{kg} \mathrm{ha}^{-1}$, resultando na quantidade de nutrientes deixados sobre a superfície do solo após a dessecação e manejo de corte com triton. Determinou-se ainda o teor de Carbono (TEDESCO et al., 1995) nas amostras iniciais, para cálculo da 
relação $\mathrm{C} / \mathrm{N}$, que é indicativo de durabilidade da palha produzida, além do teor de lignina (SILVA; QUEIROZ, 2002) para cálculo da relação lignina/N total.

Os dados foram submetidos à análise de variância pelo teste $\mathrm{F}(\mathrm{p}<0,05)$ e as médias dos atributos referentes às espécies forrageiras, foram comparadas pelo teste de Tukey $(\mathrm{p}<0,05)$. A decomposição da palhada foi avaliada conforme sugerido por Wider \& Lang (1982) na utilização do método do "Litter bag", adotando-se a equação com maior coeficiente de determinação $\left(\mathrm{r}^{2}\right)(\mathrm{p}<0,05)$. As análises estatísticas foram realizadas utilizando o software estatístico Sisvar (FERREIRA, 1999).

\section{RESULTADOS E DISCUSSÃO}

De maneira geral, os valores para produtividade de massa seca (PMS) e acúmulo de nutrientes obtidos pelas forrageiras em estudo, diferiram significativamente $(\mathrm{p}<0,05)$ quanto às espécies analisadas e épocas de semeadura durante os dois anos agrícolas avaliados, respectivamente (Tabela 2). Verifica-se que os maiores valores para PMS e consequentemente acúmulo de nutrientes, foram obtidos pela cultura do sorgo, seguido pela cultura do milheto nos dois anos agrícolas, em que a $3^{\mathrm{a}}$ época de semeadura (E3) foi a época que proporcionou também maiores valores destes atributos, devido principalmente às condições climáticas, como aumento de temperatura e precipitação pluvial durante o período de realização do experimento (Figura 1), o que proporcionou melhor desenvolvimento das culturas em questão.

A produtividade média de massa seca das espécies forrageiras nas três épocas de semeadura foram relativamente altas, podendo ser estas espécies consideradas como excelentes opções como culturas produtoras de palhada, visando à implantação ou manutenção do SPD na região em estudo. Neste contexto, Ruedell (1998) sugeriu uma adição anual em torno de $6.000 \mathrm{~kg} \mathrm{ha}^{-1}$ de massa seca, enquanto Bayer et al. (2000) sugeriram uma adição anual em torno de 10.000 a $12.000 \mathrm{~kg} \mathrm{ha}^{-1} \mathrm{de}$ massa seca, ambos na região Sul do Brasil. No entanto, em regiões de cerrado com inverno seco e quente, pela rápida decomposição dos resíduos, o aporte pode ultrapassar essas quantidades supracitadas (PARIZ et al., 2011a). Cabe destacar que o capim xaraés, embora com PMS satisfatória para utilização no SPD, foi inferior às demais forrageiras nas três épocas de semeadura (Tabela 2), contudo, esta espécie apresentou uma boa estabilidade de produção mesmo em épocas mais frias e com menor pluviosidade.

Tabela 2. Produtividade de massa seca (PMS) e acúmulo de macronutrientes na palhada de espécies forrageiras em função de épocas de semeadura. Safras 2009/2010 e 2010/2011.

\begin{tabular}{|c|c|c|c|c|c|c|c|}
\hline & PMS & $\mathbf{N}$ & $\mathbf{P}$ & $\mathbf{K}$ & $\mathbf{C a}$ & Mg & $\mathbf{S}$ \\
\hline & \multicolumn{7}{|c|}{$\mathrm{kg} \mathrm{ha}^{-1}$} \\
\hline Tratamentos & \multicolumn{7}{|c|}{ Safra 2009/2010 } \\
\hline Espécies & $* *$ & ** & $* *$ & $* *$ & ** & ** & ** \\
\hline Capim xaraés & 3.607 & 83,8 & 20,4 & 98,4 & 11,9 & 16,7 & 6,3 \\
\hline Milheto & 9.993 & 139,4 & 38,3 & 228,5 & 32,3 & 40,9 & 17,2 \\
\hline Sorgo & 10.667 & 166,4 & 53,0 & 239,4 & 34,9 & 45,0 & 13,8 \\
\hline Épocas & $* *$ & $* *$ & $* *$ & $* *$ & $* *$ & $* *$ & $* *$ \\
\hline E1 & 5.983 & 101,8 & 27,9 & 150,9 & 19,2 & 22,8 & 9,0 \\
\hline E2 & 6.667 & 114,5 & 32,2 & 145,5 & 21,5 & 27,6 & 11,0 \\
\hline E3 & 11.617 & 173,2 & 51,5 & 269,9 & 38,5 & 52,2 & 17,2 \\
\hline \multirow[t]{2}{*}{ CV(\%) } & 15,6 & 20,8 & 24,6 & 22,2 & 18,7 & 30,6 & 25,2 \\
\hline & \multicolumn{7}{|c|}{ Safra 2010/2011 } \\
\hline Espécies & $* *$ & $*$ & $*$ & $* *$ & $*$ & $*$ & $* *$ \\
\hline Capim xaraés & 3.867 & 90,7 & 8,7 & 119 & 8,9 & 12,5 & $5,4 \mathrm{~b}$ \\
\hline Milheto & 7.792 & 200,8 & 19,3 & 253 & 27,3 & 32,6 & $14,9 \mathrm{a}$ \\
\hline Sorgo & 10.827 & 231,2 & 25,2 & 285 & 30,8 & 31,9 & $13,8 \mathrm{a}$ \\
\hline Épocas & $* *$ & $*$ & $*$ & $* *$ & $*$ & $*$ & $* *$ \\
\hline E1 & 4.100 & 106,3 & 9,5 & 108 & 13,3 & 13,9 & $6,3 \mathrm{c}$ \\
\hline E2 & 6.825 & 169,7 & 17,2 & 221 & 21,7 & 24,7 & $11,6 \mathrm{~b}$ \\
\hline E3 & 11.560 & 246,1 & 26,4 & 328 & 32,1 & 34,4 & $16,3 \mathrm{a}$ \\
\hline $\mathrm{CV}(\%)$ & 35,3 & 35,8 & 38,9 & 31,6 & 36,8 & 30,6 & 31,3 \\
\hline
\end{tabular}

, $,{ }^{\text {ns }}:(\mathrm{P}<0,01),(\mathrm{P}<0,05)$ e não significativo, respectivamente. 
Em virtude da alta produtividade de massa seca (PMS) obtida pela cultura do sorgo forrageiro, principalmente na $3^{\text {a }}$ época (E3) nos dois anos agrícolas (2009/2010 e 2010/2011), constatou-se que esta combinação proporcionou os maiores acúmulos de N, P, K, Ca e Mg na biomassa seca, e portanto, tornou-se a opção mais vantajosa quando o objetivo for a reciclagem de nutrientes (Tabela 2).

Verificou-se que houve interação significativa $(\mathrm{p}<0,01)$ entre as espécies forrageiras e épocas de semeadura, cujos desdobramentos das interações demonstraram que entre as espécies forrageiras, o sorgo apresentou maior PMS em relação às demais nas duas primeiras épocas (E1 e E2) para os dois anos de avaliação, respectivamente (Tabelas 3 e 4). A cultura do milheto obteve maior PMS na terceira época (E3) de semeadura no ano agrícola 2009/2010 (Tabela 3), diferentemente do observado no ano seguinte, em que a cultura do sorgo obteve os maiores valores para PMS na terceira época de avaliação (Tabela 4). Tais resultados podem ser atribuídos provavelmente, às condições climáticas da região em estudo, pois entre as épocas de semeadura, os melhores resultados entre as espécies forrageiras foram obtidos na terceira época (E3), em que se verificou o aumento de temperatura e chuvas mais constantes nos dois anos agrícolas avaliados (Figura 1).

O capim xaraés não apresentou diferença significativa $(p>0,05)$ de acúmulo de nutrientes em nenhuma das épocas avaliadas no primeiro ano agrícola (2009/2010). Portanto, pode-se inferir que no período de setembro a outubro, a sua qualidade nutricional pouco foi alterada, mesmo em épocas de maior pluviosidade e temperatura.

Tabela 3. Desdobramento das interações significativas entre épocas de semeadura e espécies forrageiras para produtividade de massa seca (PMS) e acúmulos de N, P, K, Ca, Mg e S $\left(\mathrm{kg} \mathrm{ha}^{-1}\right)$. Safra 2009/2010.

\begin{tabular}{|c|c|c|c|}
\hline \multirow[b]{2}{*}{ Épocas } & \multicolumn{3}{|c|}{ Espécies } \\
\hline & Capim xaraés & Milheto & Sorgo \\
\hline & \multicolumn{3}{|c|}{ Produtividade de massa seca (PMS) } \\
\hline E1 & $3.500 \mathrm{aC}$ & $5.900 \mathrm{bB}$ & $8.550 \mathrm{bA}$ \\
\hline E2 & $3.250 \mathrm{aC}$ & $6.850 \mathrm{bB}$ & $9.900 \mathrm{bA}$ \\
\hline \multirow[t]{2}{*}{$\mathbf{E 3}$} & $4.250 \mathrm{aC}$ & $17.050 \mathrm{aA}$ & $13.550 \mathrm{aB}$ \\
\hline & \multicolumn{3}{|c|}{$\mathbf{N}\left(\mathrm{kg} \mathrm{ha}^{-1}\right)$} \\
\hline E1 & $81,3 \mathrm{aB}$ & $88,4 \mathrm{bAB}$ & $135,6 \mathrm{aA}$ \\
\hline $\mathbf{E 2}$ & $76,8 \mathrm{aB}$ & $131,8 \mathrm{bA}$ & $135,0 \mathrm{aA}$ \\
\hline \multirow[t]{2}{*}{ E3 } & $93,2 \mathrm{aC}$ & $279,0 \mathrm{aA}$ & $147,6 \mathrm{aB}$ \\
\hline & \multicolumn{3}{|c|}{$\mathbf{P}\left(\mathrm{kg} \mathrm{ha}^{-1}\right)$} \\
\hline E1 & $17,5 \mathrm{aB}$ & $34,18 \mathrm{bA}$ & $32,1 \mathrm{aAB}$ \\
\hline $\mathbf{E 2}$ & $18,0 \mathrm{aB}$ & $35,6 \mathrm{bA}$ & $42,9 \mathrm{aA}$ \\
\hline \multirow[t]{2}{*}{$\mathbf{E 3}$} & $25,7 \mathrm{aB}$ & $89,1 \mathrm{aA}$ & $39,8 \mathrm{aB}$ \\
\hline & \multicolumn{3}{|c|}{$K\left(\mathrm{~kg} \mathrm{ha}^{-1}\right)$} \\
\hline E1 & $100,0 \mathrm{aB}$ & $147,4 \mathrm{bAB}$ & $205,1 \mathrm{bA}$ \\
\hline $\mathbf{E 2}$ & $87,9 \mathrm{aB}$ & $150,6 \mathrm{bAB}$ & $197,8 \mathrm{bA}$ \\
\hline \multirow[t]{2}{*}{$\mathbf{E 3}$} & $107,3 \mathrm{aC}$ & $220,0 \mathrm{aA}$ & $282,7 \mathrm{aB}$ \\
\hline & \multicolumn{3}{|c|}{ Ca $\left(\mathrm{kg} \mathrm{ha}^{-1}\right)$} \\
\hline E1 & $10,2 \mathrm{aC}$ & $19,0 \mathrm{bB}$ & $28,4 \mathrm{bA}$ \\
\hline $\mathbf{E 2}$ & $10,9 \mathrm{aB}$ & $24,7 \mathrm{bA}$ & $28,7 \mathrm{bA}$ \\
\hline \multirow[t]{2}{*}{$\mathbf{E 3}$} & $14,4 \mathrm{aB}$ & $53,3 \mathrm{aA}$ & $47,6 \mathrm{aA}$ \\
\hline & \multicolumn{3}{|c|}{$\operatorname{Mg}\left(\mathrm{kg} \mathrm{ha}^{-1}\right)$} \\
\hline E1 & $15,0 \mathrm{aA}$ & $20,5 \mathrm{bA}$ & $32,9 \mathrm{bA}$ \\
\hline E2 & $16,6 \mathrm{aB}$ & $26,8 \mathrm{bAB}$ & $39,4 \mathrm{bA}$ \\
\hline \multirow[t]{2}{*}{$\mathbf{E 3}$} & $18,3 \mathrm{aB}$ & $75,4 \mathrm{aA}$ & $62,8 \mathrm{aA}$ \\
\hline & \multicolumn{3}{|c|}{$\mathrm{S}\left(\mathrm{kg} \mathrm{ha}^{-1}\right)$} \\
\hline E1 & $6,4 \mathrm{aA}$ & $9,9 \mathrm{bA}$ & $10,6 \mathrm{aA}$ \\
\hline E2 & $6,0 \mathrm{aB}$ & $11,8 \mathrm{bA}$ & $15,3 \mathrm{aA}$ \\
\hline $\mathbf{E 3}$ & $6,5 \mathrm{aC}$ & $29,9 \mathrm{aA}$ & $15,4 \mathrm{aB}$ \\
\hline
\end{tabular}

Médias seguidas de letras distintas, minúsculas na coluna e maiúsculas na linha, diferem entre si pelo teste de Tukey a $5 \%$ de probabilidade. 
Quanto ao milheto, o comportamento de efeito das épocas foi constante para todos os acúmulos nutricionais, uma vez que nas épocas mais tardias (maior pluviosidade) foram acumuladas as maiores quantidades de $\mathrm{P}, \mathrm{K}, \mathrm{Ca}$ e $\mathrm{Mg}$, diferindo significativamente $(\mathrm{p}<0,05)$ entre a $1^{\mathrm{a}}$ e a $3^{\mathrm{a}}$ épocas (E1 e E3). Já para a cultura do sorgo forrageiro, novamente no mês de outubro, pela maior PMS, o acúmulo de nutrientes foi significativamente $(p<0,01)$ superior às demais épocas de avaliação.

Comparando-se as forrageiras dentro de cada época no segundo ano de avaliação (2010/2011), nota-se que de maneira geral, a cultura do milheto e principalmente a do sorgo, pela maior PMS se destacaram no acúmulo de nutrientes, em relação ao capim xaraés, nas épocas 2 e 3 (final de setembro e meados de outubro), demonstrando a resposta destas duas espécies ao aumento de temperatura e pluviosidade. Na época 1 (início de setembro), pela escassez de água e temperaturas mais amenas, não houve variação entre o acúmulo nutricional das forrageiras em estudo (Tabela 4).

A cultura do sorgo forrageiro e do milheto apresentaram maior acúmulo de nutrientes em relação ao capim xaraés $(\mathrm{p}<0,01)$ (Tabela 4), principalmente na terceira época de semeadura (E3). No geral, o acúmulo de nutrientes das forrageiras estudadas encontram-se de acordo com os resultados obtidos por diversos pesquisadores (BRAZ et al., 2004; TORRES et al., 2005, BOER et al., 2007; PARIZ et al., 2011a), onde o macronutriente de maior acúmulo foi o potássio $(\mathrm{K})$ seguido pelo nitrogênio $(\mathrm{N})$, sendo estes nutrientes os mais absorvidos e acumulados no tecido vegetal das plantas de cobertura na região do Cerrado.

Deve-se enfatizar a contribuição do $\mathrm{K}$ liberado pelos resíduos vegetais, sendo em torno de $80 \%$ para gramíneas e $90 \%$ para leguminosas, tendo assim importante papel na ciclagem desse nutriente nos sistemas produtivos (SANTOS et al., 2008). Adicionalmente, parte do $\mathrm{N}$ e do $\mathrm{P}$ é rapidamente liberada no estádio inicial de decomposição dos resíduos vegetais (GAMA-RODRIGUES et al., 2007). Desta forma, torna-se importante salientar as elevadas quantidades de nutrientes que podem ser liberados e utilizados por culturas em sucessão, por ficarem fixados em compostos orgânicos (SILVA; MENDONÇA, 2007).

Tabela 4. Desdobramento das interações significativas entre épocas de semeadura e espécies forrageiras para produtividade de massa seca (PMS) e acúmulos de N, P, K, Ca e Mg $\left(\mathrm{kg} \mathrm{ha}^{-1}\right)$. Safra 2010/2011.

\begin{tabular}{|c|c|c|c|}
\hline \multirow[b]{2}{*}{ Épocas } & \multicolumn{3}{|c|}{ Espécies } \\
\hline & Capim xaraés & Milheto & Sorgo \\
\hline & \multicolumn{3}{|c|}{ Produtividade de massa seca (PMS) } \\
\hline E1 & $2.050 \mathrm{aA}$ & $5.000 \mathrm{bA}$ & $5.250 \mathrm{bA}$ \\
\hline $\mathbf{E 2}$ & $4.150 \mathrm{aA}$ & $8.575 \mathrm{abA}$ & $8.750 \mathrm{bA}$ \\
\hline \multirow[t]{2}{*}{$\mathbf{E 3}$} & $5.400 \mathrm{aB}$ & $9.800 \mathrm{aB}$ & $19.481 \mathrm{aA}$ \\
\hline & \multicolumn{3}{|c|}{$\mathbf{N}\left(\mathrm{kg} \mathrm{ha}^{-1}\right)$} \\
\hline E1 & $58 \mathrm{aA}$ & $140 \mathrm{aA}$ & $120 \mathrm{bA}$ \\
\hline E2 & $91 \mathrm{aB}$ & $220 \mathrm{aA}$ & $196 \mathrm{bAB}$ \\
\hline \multirow[t]{2}{*}{$\mathbf{E 3}$} & $120 \mathrm{aC}$ & $242 \mathrm{aB}$ & $377 \mathrm{aA}$ \\
\hline & \multicolumn{3}{|c|}{$\mathbf{P}\left(\mathrm{kg} \mathrm{ha}^{-1}\right)$} \\
\hline E1 & $5,3 \mathrm{aA}$ & $11,5 \mathrm{bA}$ & $11,7 \mathrm{bA}$ \\
\hline $\mathbf{E 2}$ & $9,0 \mathrm{aB}$ & $21,5 \mathrm{abA}$ & $21,0 \mathrm{bA}$ \\
\hline \multirow[t]{2}{*}{$\mathbf{E 3}$} & $11,7 \mathrm{aC}$ & $24,7 \mathrm{aB}$ & $42,7 \mathrm{aA}$ \\
\hline & \multicolumn{3}{|c|}{$\mathrm{K}\left(\mathrm{kg} \mathrm{ha}^{-1}\right)$} \\
\hline E1 & $64 \mathrm{aA}$ & $140 \mathrm{bA}$ & $120 \mathrm{cA}$ \\
\hline $\mathbf{E 2}$ & $128 \mathrm{aB}$ & $288 \mathrm{aA}$ & $247 \mathrm{bAB}$ \\
\hline \multirow[t]{2}{*}{$\mathbf{E 3}$} & $164 \mathrm{aC}$ & $332 \mathrm{aB}$ & $488 \mathrm{aA}$ \\
\hline & \multicolumn{3}{|c|}{$\mathrm{Ca}\left(\mathrm{kg} \mathrm{ha}^{-1}\right)$} \\
\hline E1 & $4,7 \mathrm{aA}$ & $19,3 \mathrm{bA}$ & $16,0 \mathrm{bA}$ \\
\hline $\mathbf{E 2}$ & $10,5 \mathrm{aB}$ & $28,0 \mathrm{abA}$ & $26,5 \mathrm{bA}$ \\
\hline \multirow[t]{2}{*}{ E3 } & $11,5 \mathrm{aC}$ & $34,7 \mathrm{aB}$ & $507 \mathrm{aA}$ \\
\hline & \multicolumn{3}{|c|}{$\operatorname{Mg}\left(\mathrm{kg} \mathrm{ha}^{-1}\right)$} \\
\hline E1 & $6,3 \mathrm{aA}$ & $19,5 \mathrm{bA}$ & $16,0 \mathrm{bA}$ \\
\hline E2 & $13,7 \mathrm{aB}$ & $33,0 \mathrm{abA}$ & $27,0 \mathrm{bAB}$ \\
\hline $\mathbf{E 3}$ & $17,5 \mathrm{aB}$ & $45,3 \mathrm{aA}$ & $52,5 \mathrm{aA}$ \\
\hline
\end{tabular}

Médias seguidas de letras distintas, minúsculas na coluna e maiúsculas na linha, diferem entre si pelo teste de Tukey a 5\% de probabilidade. 
Desta maneira, de acordo com Aidar \& Kluthcouski (2003), as espécies forrageiras tropicais, possuem extrema relevância nos sistemas produtivos, pois reciclam os nutrientes do subsolo, repõem a matéria orgânica e promovem a aração biológica do solo graças à abundância e agressividade de seus sistemas radiculares e da atividade biológica decorrente.

Normalmente, avalia-se a maior durabilidade da palha de plantas forrageiras pela sua relação $\mathrm{C} / \mathrm{N}$, onde o limite de 25 separa o fato de haver decomposição mais rápida abaixo deste valor. Assim, pode-se agrupar as espécies em duas classes, uma de decomposição mais rápida (leguminosas) e outra de decomposição mais lenta (gramíneas), sendo bem aceito um valor de relação $\mathrm{C} / \mathrm{N}$ próximo a 25, como referência de separação entre elas. Desta maneira, a quantidade de nutrientes acumulados em plantas de cobertura depende, entre diversos fatores, da espécie a ser utilizada, da fertilidade do solo, do estádio fenológico na dessecação, da quantidade depositada sobre a superfície do solo, da relação $\mathrm{C} / \mathrm{N}$ e lignina/ $\mathrm{N}$ total, da época de semeadura, além das condições climáticas de cada estudo (BOER et al., 2007, TEIXEIRA et al., 2011, PARIZ et al., 2011a).

As espécies forrageiras avaliadas na presente pesquisa apresentaram, de maneira geral, relação $\mathrm{C} / \mathrm{N}$ com valores superiores ao limite de 25 nos dois anos agrícolas respectivamente (Tabela 5), com destaque para o sorgo forrageiro, principalmente na segunda e terceiras épocas (E2 e E3) $(\mathrm{p}<0,01)$. Tais resultados podem ser atribuídos ao aumento da temperatura e acúmulo mais rápido de graus-dia (soma térmica) em função das épocas de semeadura, havendo antecipação do florescimento e, portanto, aos $45 \mathrm{DAE}$ (dias após a emergência), momento do manejo de corte das espécies forrageiras, estas se apresentavam em estádio mais avançado de maturação, apresentando maior teor de lignina em detrimento ao $\mathrm{N}$.

Assim sendo, a cultura do sorgo forrageiro foi a espécie que obteve o maior valor de relação $\mathrm{C} / \mathrm{N}$ e lignina/ $\mathrm{N}$ total, independentemente da época de semeadura, caracterizando-o como a espécie mais indicada para formação de palhada no SPD na região em estudo, uma vez que a relação $\mathrm{C} / \mathrm{N}$ mais elevada determina menor degradação desta palha pelos microrganismos do solo. Entretanto, quando o objetivo for a reciclagem rápida de nutrientes (menores relações $\mathrm{C} / \mathrm{N}$, e consequente maior degradabilidade da palhada em contato com o solo), a semeadura do capim xaraés em qualquer das 3 épocas torna-se a melhor opção neste sistema produtivo.

Tabela 5. Relação lignina/N total $(\mathrm{Lig} / \mathrm{N})$ e relação $\mathrm{C} / \mathrm{N}$ na palhada de espécies forrageiras em função de épocas de semeadura. Safras 2009/2010 e 2010/2011.

\begin{tabular}{ccccc}
\hline & \multicolumn{2}{c}{ Safra 2009/2010 } & \multicolumn{2}{c}{ Safra 2010/2011 } \\
\hline Tratamentos & Lig/N & C/N & Lig/N & C/N \\
\hline Espécies & ns & $* *$ & ns & $* *$ \\
\hline Capim xaraés & 0,52 & 37,7 & 0,89 & 18,4 \\
Milheto & 1,01 & 34,6 & 1,04 & 27,4 \\
Sorgo & 1,41 & 54,8 & 1,15 & 32,3 \\
\hline Épocas & ns & ns & ns \\
\hline E1 & 0,89 & 38,0 & 1,00 & 26,7 \\
E2 & 0,74 & 42,6 & 0,98 & 25,4 \\
E3 & 1,15 & 46,3 & 1,10 & 26,8 \\
\hline CV(\%) & 24,1 & 13,8 & 31,8 & 9,6 \\
\hline
\end{tabular}

** ${ }^{*},{ }^{\text {ns. }}$ : $(\mathrm{P}<0,01),(\mathrm{P}<0,05)$ e não significativo, respectivamente.

Como as espécies forrageiras utilizadas na presente pesquisa são todas gramíneas, provavelmente, respondem a soma térmica para indução do florescimento (STEINMETZ; MEIRELES, 1999). Portanto, os maiores valores para a relação $\mathrm{C} / \mathrm{N}$ foram verificadas na $3^{\mathrm{a}}$ época de semeadura, onde as temperaturas foram mais altas durante o ciclo de desenvolvimento das culturas (Figura 1).

Com relação à decomposição da palhada remanescente das espécies forrageiras em função de dias após o manejo de corte (DAM), verifica-se que nas três épocas avaliadas, a cultura do sorgo forrageiro obteve maior produtividade de massa seca (PMS), seguido da cultura do milheto nos dois anos de avaliação, respectivamente (safras 2009/2010 e 2010/2011) ( $<<0,01)$. Constatou-se, portanto, ajustes lineares, exponenciais e logarítmicos decrescentes para todas as espécies forrageiras durante todo o período de avaliação (Tabela 6). 
Tabela 6. Decomposição de massa seca remanescente $\left(\mathrm{kg} \mathrm{ha}^{-1}\right)$ no solo 180 dias após o manejo de corte (DAM) de espécies forrageiras em função de épocas de semeadura. Safras 2009/2010 e 2010/2011.

\begin{tabular}{|c|c|c|c|c|}
\hline & \multicolumn{2}{|l|}{ Safra 2009/2010 } & \multicolumn{2}{|l|}{ Safra 2010/2011 } \\
\hline & \multicolumn{4}{|c|}{ Capim xaraés } \\
\hline Épocas & Equação & $\mathbf{r}^{2}$ & Equação & $\mathbf{r}^{2}$ \\
\hline E1 & $\mathrm{y}=5.212,08 \mathrm{e}^{-0,0245 \mathrm{DAM}}$ & $0,955^{* *}$ & $y=-12.723 D A M+2.693,9$ & $0,871^{* *}$ \\
\hline E2 & $\mathrm{y}=5.338,62 \mathrm{e}^{-0,0260 \mathrm{DAM}}$ & $0,964^{* *}$ & $\mathrm{y}=5.109,8 \mathrm{e}^{-0,0121 \mathrm{DAM}}$ & $0,944^{* *}$ \\
\hline \multirow[t]{3}{*}{ E3 } & $\mathrm{y}=4.748,26 \mathrm{e}^{-0,0134 \mathrm{DAM}}$ & $0,977^{* *}$ & $\mathrm{y}=6.136,2 \mathrm{e}^{-0,0134 \mathrm{DAM}}$ & $0,838^{* *}$ \\
\hline & \multicolumn{4}{|c|}{ Milheto } \\
\hline & Equação & $\mathbf{r}^{2}$ & Equação & $\mathbf{r}^{2}$ \\
\hline E1 & $\mathrm{y}=6.063,20-24,784 \mathrm{DAM}$ & $0,982^{* *}$ & $\mathrm{y}=6.072,2 \mathrm{e}^{-0,0193 \mathrm{DAM}}$ & $0,979^{* *}$ \\
\hline E2 & $\mathrm{y}=7.420,39 \mathrm{e}^{-0,0119 \mathrm{DAM}}$ & $0,966^{* *}$ & $\mathrm{y}=11.243 \mathrm{e}^{-0,0162 \mathrm{DAM}}$ & $0,963^{* *}$ \\
\hline \multirow[t]{3}{*}{ E3 } & $\mathrm{y}=15.824,81 \mathrm{e}^{-0,0132 \mathrm{DAM}}$ & $0,951^{* *}$ & $y=6.542,7 \mathrm{e}^{-0,0095 \mathrm{DAM}}$ & $0,845^{* *}$ \\
\hline & \multicolumn{4}{|c|}{ Sorgo } \\
\hline & Equação & $\mathbf{r}^{2}$ & Equação & $\mathbf{r}^{2}$ \\
\hline E1 & $\mathrm{y}=8.928,81-38,17 \mathrm{DAM}$ & $0,977^{* * *}$ & $\mathrm{y}=8.068,6 \mathrm{e}^{-0,0152 \mathrm{DAM}}$ & $0,905^{* *}$ \\
\hline E2 & $\mathrm{y}=10.095,54 \mathrm{e}^{-0,0068 \mathrm{DAM}}$ & $0,973^{* *}$ & $\mathrm{y}=10.936 \mathrm{e}^{-0,0133 \mathrm{DAM}}$ & $0,924^{* *}$ \\
\hline $\mathbf{E 3}$ & $y=13.929,86+1.671,76 \operatorname{Ln}(\mathrm{DAM})$ & $0,902^{* *}$ & $\mathrm{y}=16.479 \mathrm{e}^{-0,0131 \mathrm{DAM}}$ & $0,915^{* *}$ \\
\hline
\end{tabular}

$\mathrm{y}=$ massa seca remanescente $\left(\mathrm{kg} \mathrm{ha}^{-1}\right)$ e DAM= dias após manejo da palha.

Aos 180 dias após o manejo de corte (DAM), verificou-se que a cultura do sorgo forrageiro e do milheto apresentaram menor taxa de decomposição, permanecendo sobre a superfície do solo um maior remanescente de palha quando comparado ao capim xaraés nos dois anos agrícolas $(2009 / 2010$ e 2010/2011) (p<0,01). Provavelmente, tal resultado se deva à maior produtividade de palha e, portanto, proporcionando menor contato com a superfície do solo, em que a velocidade de decomposição dos resíduos vegetais se torna mais lenta, além da maior relação $\mathrm{C} / \mathrm{N}$ e $\mathrm{Lig} / \mathrm{N}$ total apresentada por essas culturas. $\mathrm{Na} 3^{\mathrm{a}}$ época de semeadura (E3), em função da maior produtividade de massa seca total, elevadas temperaturas e pluviosidade, a decomposição foi mais acentuada, contudo o remanescente de palha da cultura do sorgo forrageiro e do milheto foram maiores que o capim xaraés (Tabela 6).

Em virtude da baixa PMS das espécies forrageiras na $1^{\text {a }}$ época de semeadura (Tabela 2), o maior contato entre palhada e solo, aliado às altas temperaturas e precipitações, principalmente nos meses de dezembro a março (Figura 1) determinaram a rápida degradação da palhada remanescente das três espécies nos dois anos avaliados, respectivamente. Assim, de modo geral, em todas as 3 épocas de semeadura, a quantidade de palhada remanescente sobre a superfície do solo atingiu valores abaixo de $2.000 \mathrm{~kg} \mathrm{ha}^{-1}$ aos 180 DAM (Tabela 6). Cabe ressaltar que a palhada remanescente protege a superfície do solo, garantindo menor variação na temperatura do solo, maior umidade e principalmente disponibilização de nutrientes durante o processo de decomposição da palhada, bem como, mineralização da matéria orgânica (TORRES et al., 2005).

As diferenças para a decomposição de palhada entre os tratamentos $(\mathrm{p}<0,01)$ durante os dois anos agrícolas podem ser atribuídas, principalmente à diferença na precipitação pluvial durante as duas safras avaliadas, em que na safra 2010/2011 houve uma maior e melhor distribuição de chuvas no período de avaliação, o que pode ter influenciado na intensificação do processo de decomposição e degradação dos resíduos vegetais.

Com relação à porcentagem de palhada remanescente no solo após o manejo de corte das espécies forrageiras, verifica-se que na $1^{\mathrm{a}}$ época, a cultura do sorgo e do milheto apresentaram um residual de palha por volta de $25 \%$ da massa seca inicial aos 180 DAM no primeiro ano de avaliação (Tabela 7), valores estes inferiores aos $52 \%$ da Urochloa brizantha aos 150 DAM verificados por Kliemann et al. (2006) em períodos de menores precipitações pluviais quando comparadas aos presente trabalho (mais de $1.000 \mathrm{~mm}$ acumulados no período de avaliação).

O capim xaraés apresentou a mais alta taxa de decomposição em todas as épocas avaliadas $(\mathrm{p}<0,01)$, principalmente a partir dos 30 DAM nos dois anos agrícolas, independentemente da época de semeadura. Tal fato se deve em função desta espécie ter apresentado os menores valores da relação $\mathrm{C} / \mathrm{N} \mathrm{e}$ relação Lig/N total, além de uma menor PMS em comparação às outras espécies, fazendo com que houvesse uma menor quantidade de palhada sobre o solo, aumentando o contado desta com a superfície, consequentemente acelerando a velocidade de decomposição dos resíduos vegetais. 
Tabela 7. Percentual de palha remanescente $\left(\mathrm{kg} \mathrm{ha}^{-1}\right)$ no solo 180 dias após o manejo de corte (DAM) de espécies forrageiras em função de épocas de semeadura. Safras 2009/2010 e 2010/2011.

Safra 2009/2010

Safra 2010/2011

\begin{tabular}{|c|c|c|c|c|}
\hline & \multicolumn{2}{|l|}{ Safra $2009 / 2010$} & \multicolumn{2}{|c|}{ Safra 2010/2011 } \\
\hline & \multicolumn{4}{|c|}{ Capim xaraés } \\
\hline Épocas & Equação & $\mathbf{r}^{2}$ & Equação & $\mathbf{r}^{2}$ \\
\hline E1 & $\mathrm{y}=148,92 \mathrm{e}^{-0,0245 \mathrm{DAM}}$ & $0,955^{* *}$ & $y=107,04-0,051 \mathrm{DAM}$ & $0,871^{* *}$ \\
\hline $\mathbf{E 2}$ & $y=164,26 e^{-0,0260 D A M}$ & $0,964^{* *}$ & $\mathrm{y}=107,95 \mathrm{e}^{-0,0121 \mathrm{DAM}}$ & $0,944^{* *}$ \\
\hline \multirow[t]{3}{*}{$\mathbf{E 3}$} & $\mathrm{y}=111,72 \mathrm{e}^{-0,0134 \mathrm{DAM}}$ & $0,977^{* *}$ & $\mathrm{y}=114,16 \mathrm{e}^{-0,0134 \mathrm{DAM}}$ & $0,839^{* *}$ \\
\hline & \multicolumn{4}{|c|}{ Milheto } \\
\hline & Equação & $\mathbf{r}^{2}$ & Equação & $\mathbf{r}^{2}$ \\
\hline E1 & $\mathrm{y}=102,77-0,4201 \mathrm{DAM}$ & $0,982^{* *}$ & $\mathrm{y}=115,48 \mathrm{e}^{-0,0193 \mathrm{DAM}}$ & $0,979^{* *}$ \\
\hline E2 & $\mathrm{y}=108,33 \mathrm{e}^{-0,0119 \mathrm{DAM}}$ & $0,966^{* *}$ & $\mathrm{y}=131,12 \mathrm{e}^{-0,0162 \mathrm{DAM}}$ & $0,963^{* *}$ \\
\hline \multirow[t]{3}{*}{$\mathbf{E 3}$} & $\mathrm{y}=92,81 \mathrm{e}^{-0,0132 \mathrm{DAM}}$ & $0,951^{* *}$ & $\mathrm{y}=67,68 \mathrm{e}^{-0,0095 \mathrm{DAM}}$ & $0,845^{* *}$ \\
\hline & \multicolumn{4}{|c|}{ Sorgo } \\
\hline & Equação & $\mathbf{r}^{2}$ & Equação & $\mathbf{r}^{2}$ \\
\hline E1 & $\mathrm{y}=104,43-0,446 \mathrm{DAM}$ & $0,977^{* *}$ & $\mathrm{y}=98,99 \mathrm{e}^{-0,0058 \mathrm{DAM}}$ & $0,885^{* *}$ \\
\hline $\mathbf{E 2}$ & $\mathrm{y}=101,98 \mathrm{e}^{-0,0068 \mathrm{DAM}}$ & $0,973^{* *}$ & $y=107,21 e^{-0,0133 D A M}$ & $0,924^{* *}$ \\
\hline $\mathbf{E 3}$ & $y=102,80-12,338 \mathrm{Ln}(\mathrm{DAM})$ & $0,902^{* *}$ & $\mathrm{y}=83,79 \mathrm{e}^{-0,0131 \mathrm{DAM}}$ & $0,915^{* *}$ \\
\hline
\end{tabular}

$\mathrm{y}=\%$ de massa seca remanescente $\left(\mathrm{kg} \mathrm{ha}^{-1}\right)$ e DAM= dias após manejo da palha.

Em geral, a decomposição da palha das espécies forrageiras nas três épocas de semeadura, acompanhou a produtividade de massa seca total, sendo que quanto mais palha produzida $\left(\mathrm{kg} \mathrm{ha}^{-1}\right)$, maior remanescência aos 180 DAM. A cultura do milheto e do sorgo forrageiro, apresentaram no processo de decomposição da palhada, resultados semelhantes aos verificados no capim xaraés, deixando ao final do período de 180 DAM valores entre 5 e $20 \%$ de palha remanescente. Independentemente da época de semeadura, para todas as espécies forrageiras, $50 \%$ da palhada remanescente foi degradada até os 60 DAM (Tabela 7).

Kliemann et al. (2006), estudando taxas de decomposição de resíduos de espécies de cobertura no Cerrado, em LATOSSOLO VERMELHO distroférrico, verificaram que as palhadas mais frágeis e menos persistentes, em ordem decrescente, foram do capim mombaça, sorgo granífero, milheto, estilosantes, guandu e capim marandu em cultivo exclusivo e em consórcio com milho. Neste mesmo trabalho, aos 150 DAM a ordem decrescente de decomposição foi: sorgo (80\%), estilosantes (72\%), guandu (65\%), capim-mombaça (64\%), milheto (58\%), capim marandu em cultivo exclusivo (56\%) e em cultivo consorciado com milho (48\%), sendo estes resultados semelhantes aos verificados na presente pesquisa.

De modo geral, em função das altas temperaturas e precipitações pluviais durante o período de avaliação (Figura 1), o comportamento de degradação das espécies forrageiras em função das épocas de semeadura, durante os dois anos agrícolas, demonstraram que estas espécies são viáveis em sistemas produtivos semelhantes aos verificados na presente pesquisa, pois demonstraram produção de palhada em quantidades satisfatórias à adoção, manutenção ou continuidade do SPD, além da produção satisfatória de nutrientes acumulados pela biomassa vegetal, beneficiando os sistemas produtivos como um todo, podendo favorecer as culturas semeadas em sucessão.

Assim, a permanência da palhada sobre a superfície do solo é um fator de extrema relevância para a manutenção e a proteção do sistema soloplanta, beneficiando a manutenção da umidade, favorecendo a biota do solo e a ciclagem de nutrientes (KLIEMANN et al., 2006). Esse fato reforça a preocupação de se produzir palhada com decomposição mais lenta, o que significa mantê-la sobre o solo por maior período de tempo (TORRES et al., 2005).

\section{CONCLUSÕES}

As maiores produtividades de massa seca e acúmulos de nutrientes foram obtidos pela cultura do sorgo forrageiro nas três épocas de semeadura.

A cultura do sorgo forrageiro apresentou os maiores valores da relação $\mathrm{C} / \mathrm{N}$ e lignina/ $\mathrm{N}$ total, principalmente nas $2^{\mathrm{a}}$ e $3^{\mathrm{a}}$ épocas, nos dois anos agrícolas, proporcionando menor degradação da palhada em comparação ao milheto e ao capim xaraés.

A decomposição da palhada foi mais lenta para o sorgo forrageiro e o milheto. Independentemente da espécie forrageira e da época de semeadura, a deposição inicial de massa seca das espécies forrageiras foram adequadas para utilização 
destas espécies no sistema plantio direto, nas condições climáticas de cerrado de baixa altitude.

\section{AGRADECIMENTOS}

À FAPESP pela concessão de bolsa de iniciação científica ao terceiro autor e pelo apoio financeiro ao projeto (Processo $n^{\circ}$ 09/11204-3).

\begin{abstract}
In order to identify the productive potential of the forages Sorghum bicolor (L.) Moench, Pennisetum glaucum (L.) R. Br and Urochloa brizantha cv. Xaraés due to sowing times, as well as the subsequent formation of straw for no tillage system continuity, evaluated the dry mass production, the relation of $\mathrm{C} / \mathrm{N}$ and lignin/ $\mathrm{N}$ total, the nutrients accumulation and straw decomposition in two agricultural seasons. The experiment was conducted in Selvíria - MS $\left(20^{\circ} 18^{\prime} \mathrm{S}\right.$ and $51^{\circ} 22^{\prime} \mathrm{W}$, with an altitude of $\left.370 \mathrm{~m}\right)$, in a Dark Red Dystrophic Latosol. A randomized block design was adopted in a $3 \times 3$ factorial scheme consisting of three species of forage plants: sorghum (Sorghum bicolor (L.) Moench), pearl millet (Pennisetum glaucum (L.) R. Br ) and grass xaraés (Urochloa brizantha cv. Xaraés) and three sowing times (1st season - 09.14.09 (E1), 2nd season - 09.29.09 (E2) and 3rd season - 10.14.09 (E3), managed 45 days after emergence - DAE), with 4 replications. For the second growing season (2010/2011), was used the same forages species and experimental design, with the following sowing times: 1st season - 09.10.10 (E1), 2nd season - 09.27.10 (E2) and 3rd season - 10.20.10 (E3), respectively. The highest yield dry mass and nutrient accumulation were obtained by the forage sorghum culture in the three sowing times. The forage sorghum culture presented the highest values of $\mathrm{C} / \mathrm{N}$ and lignin/ $\mathrm{N}$ total, mainly in the 2nd and 3rd seasons, in both years, providing less straw degradation compared to pearl millet and xaraés grass. The straw decomposition was slower for the forage sorghum and pearl millet. Regardless of forage species and sowing time, the initial dry mass deposition of forage species were suitable for these species in the no tillage system, in climatic conditions of of low altitude cerrado.
\end{abstract}

KEYWORKS: Sorghum bicolor. Pennisetum glaucum. Urochloa brizantha. No tillage system.

\title{
REFERÊNCIAS
}

AIDAR, H.; KLUTHCOUSKI, J. Evolução das atividades lavoureiras e pecuária nos cerrados. In: KLUTHCOUSKI, J.; STONE, L. F.; AIDAR, H. Integração Lavoura-Pecuária. 1. ed. Santo Antônio de Goiás: Embrapa Arroz e Feijão, 2003. cap.01, p. 25-58.

BAYER, C.; MIELNICZUK, J.; AMADO, T. J. C.; MARTINNETO, L.; FERNANDES, S. V. Organic matter storage in a sandy clay loam Acrisol affected by tillage a cropping systems in southern Brazil. Soil and Tillage Research, Amsterdam, v. 54, p. 101-109, 2000. http://dx.doi.org/10.1016/S0167-1987(00)00090-8

BOER, C. A.; ASSIS, R. L.; SILVA, G. P.; BRAZ, A. J. B. P.; BARROSO, A. L. L.; CARGNELUTTI FILHO, A.; PIRES, F. R. Ciclagem de nutrientes por plantas de cobertura na entressafra em um solo de cerrado. Pesquisa Agropecuária Brasileira, Brasília, v. 42, n. 9, p. 1269-1276, 2007. http://dx.doi.org/10.1590/S0100204X2007000900008

BRAZ, A. J. B. P.; SILVEIRA, P.; KLIEMANN, H. J.; ZIMMERMANN, F. J. P. Acumulação de nutrientes em folhas de milheto e dos capins braquiária e mombaça. Pesquisa Agropecuária Tropical, Goiânia, v.34, n. 2, p. 83-87, 2004.

CALVO, C. L.; FOLONI, J. S. S.; BRANCALIÃO, S. R. Produtividade de fitomassa e relação c/n de monocultivos e consórcios de guandu-anão, milheto e sorgo em três épocas de corte. Bragantia, Campinas, v. 69, n. 1, p. 77-86, 2010. http://dx.doi.org/10.1590/S0006-87052010000100011

COSTA, N. R.; ANDREOTTI, M.; GAMEIRO, R. A.; PARIZ, C. M.; BUZETTI, S.; LOPES, K. S. M. Adubação nitrogenada no consórcio de milho com duas espécies de braquiária em sistema plantio direto. Pesquisa Agropecuária Brasileira, Brasília, v. 47, n. 8, p. 1038-1047, 2012. http://dx.doi.org/10.1590/S0100204X2012000800003 
EMPRESA BRASILEIRA DE PESQUISA AGROPECUÁRIA - EMBRAPA. Manual de métodos de análise do solo. 2.ed. Rio de Janeiro, CNPS, 1997. 212p.

EMPRESA BRASILEIRA DE PESQUISA AGROPECUÁRIA - Embrapa. Sistema Brasileiro de Classificação de Solos. 3 ed. Brasília, DF: Embrapa, 2013. 353 p.

FERREIRA, D. F. SISVAR: Sistema de análise de variância. Lavras: UFLA/DEX, 1999.

GAMA-RODRIGUES, A. C.; GAMA-RODRIGUES, E. F.; BRITO, E. C. Decomposição e liberação de nutrientes de resíduos culturais de plantas de cobertura em Argissolo Vermelho-Amarelo na região Noroeste Fluminense (RJ). Revista Brasileira de Ciência do Solo, Viçosa, v. 31, p. 1421-1428, 2007.

KLIEMANN, H. J.; BRAZ, A. J. B. P.; SILVEIRA, P. M. Taxa de composição de resíduos de espécies de cobertura em Latossolo Vermelho Distroférrico. Pesquisa Agropecuária Tropical, Goiânia, v. 36, n. 1, p. 21$28,2006$.

MACEDO, M. C. M. M. Integração lavoura e pecuária: o estado da arte e inovações tecnológicas. Revista Brasileira de Zootecnia, Viçosa, v. 38, p. 133-146, 2009.

MALAVOLTA, E.; VITTI, G. C.; OLIVEIRA, S. A. Avaliação do estado nutricional das plantas: princípios e aplicações. 2ed. Piracicaba: Associação Brasileira para Pesquisa da Potassa e do Fosfato, 1997. 319 p.

PACHECO, L. P.; PIRES, F. R.; MONTEIRO, F. P.; PROCOPIO, S. O.; ASSIS, R. L.; CARMO, M. L.; PETTER, F. A. Desempenho de plantas de cobertura em sobressemeadura na cultura da soja. Pesquisa Agropecuária Brasileira, Brasília, v. 43, n. 7, p. 815-823, 2008. http://dx.doi.org/10.1590/S0100204X2008000700005

PARIZ, C. M.; ANDREOTTI, M.; BUZETTI, S.; BERGAMASCHINE, F. A.; ULIAN, N. A.; FURLAN, L. C.; MEIRELLES, P. R. L.; CAVASANO, F. A. Straw decomposition of nitrogen-fertilized grasses intercropped with irrigated maize in an integrated crop livestock system. Revista Brasileira de Ciência do Solo, Viçosa, v. 35, p. 2029-2037, 2011a.

PARIZ, C. M.; AZENHA, M. V.; ANDREOTTI, M.; ARAÚJO, F. C. M.; ULIAN, N. A.;

BERGAMASCHINE, A. F. Produção e composição bromatológica de forrageiras em sistema de integração lavoura-pecuária em diferentes épocas de semeadura. Pesquisa Agropecuária Brasileira, Brasília, v. 46, n. 10, p. 1392-1400, 2011b. http://dx.doi.org/10.1590/S0100-204X2011001000037

RAIJ, B. van; ANDRADE, J. C.; CANTARELLA, H.; QUAGGIO, J. A. Análise química para avaliação da fertilidade de solos tropicais. Campinas, Instituto Agronômico, 2001. 284p.

RUEDELL, J. A soja numa agricultura sustentável. In: SILVA, M. T. B., ed. A soja na rotação de culturas no plantio direto. Cruz Alta, Fundacep/Fecotrigo, 1998. p.1-34.

SANTOS, F. C.; NEVES, J. C. L.; NOVAIS, R. F.; ALVAREZ V. H.; SEDIYAMA, C. S. Modelagem da recomendação de corretivos e fertilizantes para a cultura da soja. Revista Brasileira de Ciência do Solo, Viçosa, v. 32, p. 1661-1674, 2008.

SILVA, I. R.; MENDONÇA, E. S. Matéria orgânica do solo. In: NOVAIS, R. F.; V. ALVARES, V. H.; BARROS, N. F.; FONTES, R. L. F.; CANTARUTTI, R. B.; NEVES, J. C. L., eds. Fertilidade do solo. 1.ed. Viçosa, MG, SBCS, 2007. p.275-374.

SILVA, D. J.; QUEIROZ, A. C. Análise de Alimentos: Métodos Químicos e Biológicos. Viçosa: UFV, 2002. $235 \mathrm{p}$. 
STEINMETZ, S.; MEIRELES, E. J. L. Clima. In: VIEIRA, N. R. A; SANTOS, A. B.; SANT'ANA, E. P. A cultura do arroz no Brasil. Santo Antônio de Goiás: EMBRAPA/CNPAF, cap.3, 1999. p. 58-87.

TEDESCO, M. J.; GIANELLO, C.; BISSANI, C. A.; BOHNEN, H.; VOLKWEISS, S. J. Análises de solo, plantas e outros materiais. 2ed. Porto Alegre: Departamento de Solos, UFRGS, 1995. 174p.

TEIXEIRA, M. B.; LOSS, A.; PEREIRA, M. G.; PIMENTEL, C. Decomposição e liberação de nutrientes da parte aérea de plantas de milheto e sorgo. Revista Brasileira de Ciência do Solo, Viçosa, v. 35, p.867-876, 2011.

TORRES, J. L. R.; PEREIRA, M. G.; ANDRIOLI, I.; POLIDORO, J. C.; FABIAN, A. J. Decomposição e liberação de nitrogênio de resíduos culturais de plantas de cobertura em um solo de cerrado. Revista Brasileira de Ciência do Solo, Viçosa, v. 29, p. 609-618, 2005.

WIDER, R. K.; LANG, G. E. A critique of the analytical methods used in examining decomposition data obtained from litter bags. Ecological Society of America, v. 63, p. 1636-1642, 1982.

http://dx.doi.org/10.2307/1940104 